2015

\title{
The Math You Need, When You Need It (TMYN): Leveling the Playing Field
}

Jennifer M. Wenner

University of Wisconsin Oshkosh, wenner@uwosh.edu

Eric M. D. Baer

Highline College, ebaer@highline.edu

Follow this and additional works at: https://digitalcommons.usf.edu/numeracy

Part of the Earth Sciences Commons, Mathematics Commons, and the Science and Mathematics Education Commons

\section{Recommended Citation}

Wenner, Jennifer M., and Eric M. Baer. "The Math You Need, When You Need It (TMYN): Leveling the Playing Field." Numeracy 8, Iss. 2 (2015): Article 5. DOI: http://dx.doi.org/10.5038/1936-4660.8.2.5 


\title{
The Math You Need, When You Need It (TMYN): Leveling the Playing Field
}

\begin{abstract}
The Math You Need, When You Need It (TMYN) is a set of online tutorials designed to help students develop and review mathematical skills that are applied in undergraduate geoscience courses. We present results of a three-year study of more than 4000 students in 106 geoscience courses at a variety of post-secondary schools who were assigned TMYN tutorials as supplemental mathematics instruction. Changes in student scores from pre- to post-test suggest that the support provided by programs such as TMYN can begin to reduce the gap between mathematically well-prepared and underprepared students; in essence, TMYN levels the quantitative playing field for all geoscience students. On average, both highand low-performing students who fully participated in the use of TMYN as a part of their course showed learning gains, although gains were larger for students who performed poorly on the pre-test. Our findings emphasize the conclusion that students who interact with context-specific quantitative problems can potentially improve their mathematical skills, regardless of initial level of mathematical preparation. We suggest that this type of support could generalize to other science courses.
\end{abstract}

\section{Keywords}

Quantitative skills, Geoscience, Online mathematics tutorials

Creative Commons License

(c) (1) (3)

This work is licensed under a Creative Commons Attribution-Noncommercial 4.0 License

\section{Cover Page Footnote}

Jennifer M. Wenner is a Professor of Geology at the University of Wisconsin Oshkosh and has been active in designing, creating and editing The Math You Need since its inception in 2006. Her research currently focuses on teaching quantitative skills in the geosciences and the geochemistry of primitive basalts in the southern Cascades.

Dr. Eric Baer is an Instructor in the Geology Program at Highline College. The Math You Need grew out of a program he started at Highline and he is one of the co-creators and editors of the website. He currently researches quantitative literacy in the geosciences and is a member of the leadership team for the SAGE $2 Y C$ program. 


\section{Introduction}

Geoscience courses on post-secondary campuses have long been referred to as “Rocks for Jocks” (e.g., DeLaughter et al. 1998; Gilbert et al. 2012), implying a paucity of "real" science and the quantitative skills that go along with the pursuit of scientific endeavors. Yet, the geosciences encompass the practical application of biology, chemistry, mathematics, and physics (sciences often perceived to be more quantitatively rigorous than geosciences) to the study of the Earth. For more than two decades, the geoscience education community has been pushing for more realistic representations of the quantitative nature of the geosciences in college courses (e.g., Shea 1990; Vacher 1998; Bailey 2000; Lutz and Srogi 2000; Macdonald et al. 2000; Baer et al. 2002; Manduca et al. 2008; Wenner et al. 2009). However, in order to increase the quantitative content of geoscience classes, faculty must be able to address the wide range of students' mathematical preparation, support students as they apply or transfer mathematics concepts in unfamiliar contexts (Bransford et al. 1999; Fike and Fike 2008; Planty et al. 2008) and find multiple ways to expose students to the power of mathematics as a tool to solve problems in STEM disciplines (Manduca et al. 2008).

The challenge that faces faculty who teach quantitative geoscience courses is to offer adequate opportunities for students to explore the power of mathematics applied to scientific problems and still retain sufficient class time to cover appropriate content. Striking a balance between stimulating mathematically prepared students while assisting those who are underprepared requires creative solutions that encourage students to succeed at the application of mathematics in geoscience contexts (Wenner et al. 2009). The use of web-based resources can afford opportunities for "just-in-time" instruction (Kaseberg 1999; Mueller and Brent 2004) and provide students with context-rich mathematical problems solved at the student's pace with immediate application in the subsequent class meeting. Providing occasions to apply mathematics to well-conceived contextual examples throughout science courses can also increase students' motivation and selfefficacy (Perin 2011; Wenner et al. 2011). When students are motivated, supported and effective at addressing quantitative problems, the inequalities in student skills can be reduced so that students find themselves on a more level playing field, able to address the quantitative problems necessary for deep learning in the geosciences.

This paper presents results of multiple successful interventions that employed web-based, asynchronous tutorials to help students review and apply basic quantitative concepts to geological problems in geoscience courses. We present a study of 106 geoscience courses at 37 two- and four-year higher education institutions between Fall 2010 and Fall 2013. The implementations in this study demonstrate effective application of geoscience-based mathematics tutorials in 
The Math You Need, When You Need It [TMYN], which provides support to students enrolled in associated courses. The results suggest that effective quantitative support should focus on application of mathematics to relevant STEM disciplinary topics. This disciplinary focus facilitates transfer of preexisting and learned mathematics to a wide variety of scientific problems and, therefore, increases students’ proficiency and success with quantitative science.

\section{The Math You Need, When You Need It}

The Math You Need, When You Need It is an online resource ${ }^{1}$ that provides quantitative instruction to students enrolled in geoscience courses. Since 2010, TMYN modules have been implemented in a wide variety classes across the geoscience curriculum. Through TMYN, students with disparate mathematical skills learn, review and gain skills, applying basic mathematics to solve quantitative, contextualized geologic problems. Because the geosciences provide a breadth of scientific topics, mathematical skills addressed by TMYN (Table 1) are applied in multiple contexts and can be adapted to a range of geoscience courses. The range of geoscience topics and the modular nature of TMYN allow instructors to choose appropriate quantitative modules (Table 1), to assign them in any order, and to build quantitative activities and assessments around geoscience topics already in a course syllabus.

Table 1

Quantitative modules available through TMYN

\begin{tabular}{|c|c|}
\hline Module Name & Web address \\
\hline Calculating Density & http://serc.carleton.edu/mathyouneed/density/ \\
\hline Graphing (three sub-modules) & http://serc.carleton.edu/mathyouneed/graphing/ \\
\hline - Plotting Points & http://serc.carleton.edu/mathyouneed/graphing/plotting.html \\
\hline - Constructing a Best Fit Line & http://serc.carleton.edu/mathyouneed/graphing/bestfit.html \\
\hline - Reading a Point from a Curve & http://serc.carleton.edu/mathyouneed/graphing/interpret.htm \\
\hline Hypsometric Curve & $\underline{\text { serc.carleton.edu/mathyouneed/hypsometric/ }}$ \\
\hline Rates & http://serc.carleton.edu/mathyouneed/rates/ \\
\hline Rearranging equations & http://serc.carleton.edu/mathyouneed/equations/ \\
\hline $\begin{array}{l}\text { Slope and topographic maps (two } \\
\text { sub-modules) }\end{array}$ & http://serc.carleton.edu/mathyouneed/slope/ \\
\hline $\begin{array}{c}\cdot \text { Calculating Slope from a } \\
\text { Topographic Map }\end{array}$ & http://serc.carleton.edu/mathyouneed/slope/slopes.html \\
\hline $\begin{array}{l}\text { - Constructing a Topographic } \\
\text { Profile }\end{array}$ & http://serc.carleton.edu/mathyouneed/slope/topoprofile.html \\
\hline Trigonometry & http://serc.carleton.edu/mathyouneed/trigonometry/ \\
\hline Unit Conversions & http://serc.carleton.edu/mathyouneed/units/ \\
\hline
\end{tabular}

${ }^{1}$ http://serc.carleton.edu/mathyouneed/index.html (last accessed June 1, 2015) 


\section{Student-Oriented Modules}

TMYN modules are open-access, student-centered, web-based tutorials designed to support self-paced, “just-in-time” student learning (e.g., Kaseberg 1999; Mueller and Brent 2004). Each module includes three student-oriented pages: (1) an introduction to the quantitative concept, (2) worked practice problems, and (3) a culminating post-module quiz.

Pages devoted to introducing the quantitative concept are steeped in online/multimedia theory (e.g., Mayer 2001) and mathematical pedagogies (e.g., Harel 1998; Kaseberg 1999; Mueller and Brent 2004). Each page addresses motivation for learning the concept, introduces a problem-solving algorithm for approaching geoscience problems with similar mathematical underpinnings (including steps that require assessment and evaluation), and walks students through using the "rules" to solve a preliminary contextual problem (Fig. 1). This initial exposure to a specific mathematical concept and related geoscience topics is the first opportunity for students to discover, relearn, or review the quantitative skills needed in their geoscience courses. Providing and supporting the use of an algorithm promotes struggling students' success, which can increase confidence and self-efficacy when solving quantitative problems (Wigfield and Eccles 2000; Wenner et al. 2011). In addition to the mechanics behind the mathematics, introductory pages are also designed to support long-term learning by connecting contextual geoscience knowledge with conceptual mathematics.

Contextual geoscience application and transfer of mathematical concepts are underscored on the second student-oriented page - the practice problems page. Here, students engage with a page of contextualized practice problems, solved using the provided algorithm (Fig. 1). Drawing on many sub-disciplines within the geosciences, each practice-problems page offers at least three distinct contextual examples, promoting application of math concepts among applications. The practice problems provide students with the opportunity to immediately apply the mathematical concept they learned on the introductory page to a new context; the design of these problems draws on the successful mathematical just-in-time approach to problem solving (Kaseberg 1999; Mueller and Brent 2004) and the necessity principle - that students are better poised for learning when there is an immediate application (Harel 1998, 2000). The geosciences are rich in examples of basic quantitative skills and provide a breadth of scientific contexts; instructors often revisit mathematical concepts multiple times in the same course and TMYN facilitates connections among topics. Repeated exposure to mathematical concepts in multiple contexts has been shown to increase long-term retention (Kenyon 2000; Stevens 2000; Steen 2004), boost student motivation (Wigfield and Eccles 2000; Barkley 2010) and improve transfer of learning (e.g., Salomon and Perkins 1989; Bransford et al. 1999). 


\section{Figure 1. REARRANGING EQUATIONS: an example module}

Equations are widely used in geoscience (as well as other STEM disciplines); from calculating rates of plate motion or groundwater flow to complex calculations of isostasy. Students often struggle with this relatively basic mathematical concept because it involves algebra and unfamiliar variables important in the Earth.

\section{Introduction Page (http://serc.carleton.edu/mathyouneed/equations/index.html)}

The Rearranging Equations module begins by addressing students' fear of equations and explaining that equations are important tools for understanding the natural world.

\section{How do I isolate $x$ (or $\mathrm{P}$ or $\mathrm{T}_{\text {.... }}$ ) in a formula? \\ Rearranging equations to solve for a given variable}

\section{Equations as important geological tools}

Sometimes, it may seem like your geoscience instructor is speaking another language when he/she talks about equations or formulae. Especially if he/she expects you to "manipulate" or rearrange them! But,

equations can provide powerful tools for describing the natural world. In the geosciences, we can describe the behavior of many natural phenomena by writing an equation for a line $(\boldsymbol{y}=\boldsymbol{m} \boldsymbol{x}+\boldsymbol{b})$, or with

exponential functions $\left(\boldsymbol{y}=\mathbf{e}^{x t}\right)$. And with a little algebra, we can rearrange those equations to solve for ANY of the variables in them.

Although this may seem like magic, you don't have to be a "mathemagician" to do this. This page is

designed to give you some tools to call upon to help you to learn some simple steps to help you to solve an

equation for any of the variables (letters that represent the element or quantity of interest).

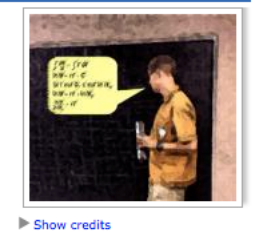

The module emphasizes the importance of manipulating equations before inserting numbers; thereby creating a "new" equation that can be used in a variety of applications. This page also includes a review of rules for algebraic manipulation with some conceptual explanation of why it works. A step-by-step procedure is subsequently embedded in a worked practice problem (with hidden answers).

Some simple steps for manipulating equations
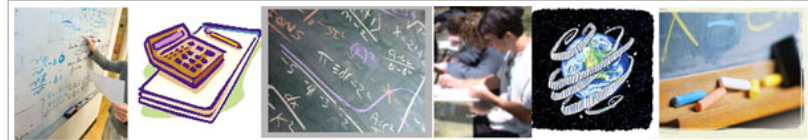

Here are some simple steps for manipulating equations. Under each step you will find an example of how to do this with an example that uses the geologic context of density (a measure of mass per unit volume).

1. Assess what you have (which of the variables do you have values for?, what units are present?, etc.). DO NOT plug in any numbers yet!

$\checkmark$ Show me how to do this

2. Determine which of the variables you want as your answer. (What is the question asking you to calculate? What is the unknown variable?) \Show me how to do this

3. Rearrange the equation so that the unknown variable is by itself on one side of the equals sign $(=)$ and all the other variables are on the other side. RULE \#1: you can add, subtract, multiply and divide by anything, as long as you do the same thing to both sides of the equals sign. - Show me how to do this

4. NOW plug in the numbers! Replace known variables with their values and don't forget to keep track of units! Show me how to do this

5. Determine the value of the unknown variable by performing the mathematical functions. That is, add, subtract, multiply and divide according to the equation you wrote for step 2 . -Show me how to do this

6. Ask yourself whether the answer is reasonable in the context of what you know about the geosciences and how much things should weigh. show me how to do this 


\section{Practice Problems Page (http://serc.carleton.edu/mathyouneed/equations/ManEqSp.html)}

When students have completed the introductory page, they are directed to the practice problem page where they find several other geoscience-related practice problems. A series of practice problems using the procedure in at least three distinct contexts is linked from the Introduction Page and are included in a linked PDF file that includes steps for solving them. The Practice Problem page for Rearranging Equations includes worked problems involving simple rates, density, and a more complicated isostasy equation. Each example problem is worked through using the steps outlined on the Introduction Page (see above) with the answers "hidden" until the student clicks on a "show" button to see how to do each step. When they have completed the problems, students can follow links to other examples at similar websites, or to the assessment.

\section{Solving for any variable... Rearranging Equations - Practice Problems}

Practice rearranging equations below using the "rules" that you have just learned. Answers are provided (but try doing them on your own before peeking!) You can download a sheet with all the questions (Acrobat (PDF) 127kB Ju125 09) so you can print them out to try on your own.

\section{Velocity, distance and time}

Many problems in the geosciences deal with the concept of velocity, from stream flow to plate motion. Being able to manipulate the equation for velocity $(v=d / t)$ gives you a powerful tool for understanding the world around you. And there are two other equations that you can get by rearranging the equation that you probably already know for velocity (also rate)!

Problem 1:Generally, we know the equation for velocity (a rate) to be:

$$
v=\frac{d}{t}
$$

Where $v=$ velocity, $d=$ distance and $t=$ time.

This equation can be rearranged so that you have an equation for distance (d) and time (t).

1. Rearrange the velocity equation to create an equation for distance (d). $\checkmark$ Show me how

2. Rearrange the velocity equation to create an equation for time ( $t)$. Show me how

Use the equations that you manipulated above to solve the following problems:

Problem 2:A wave traveling downward from the surface of the ocean at 1.5 $\mathrm{km} / \mathrm{sec}$ takes six seconds to reflect off the ocean floor. How deep is the ocean at that site?

- Show me how to calculate the depth

Problem 3:Imagine that you are working with Ms. Homeowner to understand the groundwater flow in her area. She is particularly interested in an underground tank that is located $2.6 \mathrm{~km}$ from her home. You have measured the velocity of the groundwater to be $0.033 \mathrm{~km} / \mathrm{day}$. About how long will it take any contaminants leaking from the tank to reach Ms. Homeowner's well?

-Show me how to calculate how long

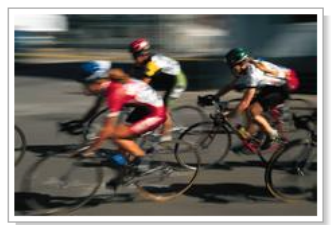

\section{Assessment (post-module quizzes)}

(https://www.wamap.org/ - Requires account, contact authors for information)

Instructors create their own, course-specific assessments. Assessment questions that have been tested and written by users of TMYN can be found in the WAMAP library. They include questions in which students choose the rearranged equation they will use and then apply it to solving the given problem, promoting use of the algorithm (Table 2). 
Table 2

Examples of Problems Used in The Math You Need Assessments

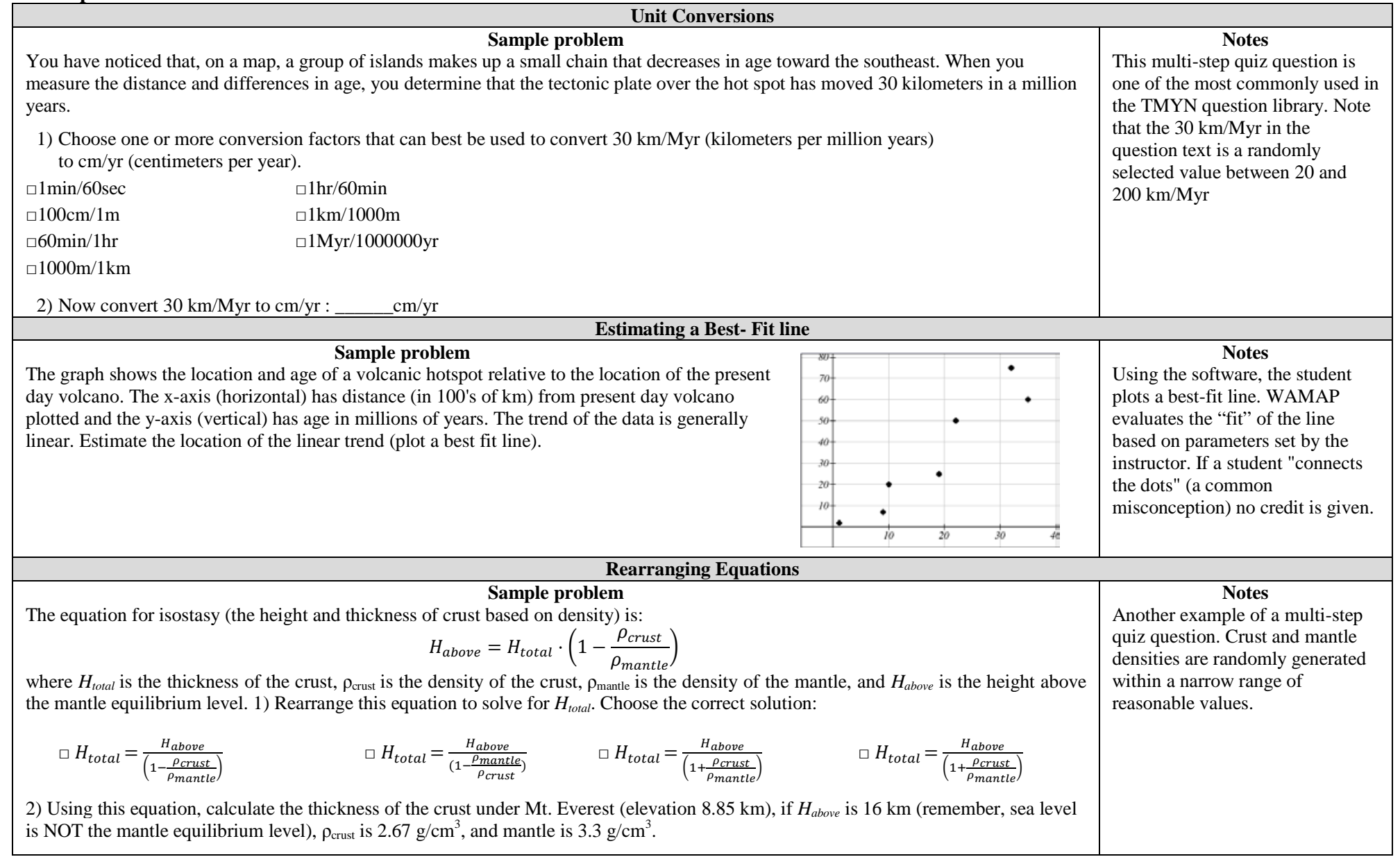


Each TMYN module culminates in a graded online post-module quiz with questions that include intermediate steps in the algorithm as well as contextual problems. Quiz questions associated with TMYN are framed in the context of geoscience application. There are no questions that simply ask the student to complete mathematical operations (e.g., "solve for $x$ ”); instead, quiz (and pre- and post-test) questions take the form of "word problems" that require assessment, decision-making, and evaluation of one's answer (Table 2). Instructors administer quizzes using the free, open-source Washington Mathematics Assessment Program, WAMAP. ${ }^{2}$ The majority of students in this study were allowed to take the post-module quizzes multiple times, promoting mastery, success and selfefficacy at solving scientifically relevant problems.

\section{Study Design}

Our study assesses whether the use of TMYN effectively (1) improves geoscience students' basic mathematical skills, (2) helps students apply mathematical skills to contextual problems, and (3) provides appropriate support and skill development (i.e., levels the playing field) for geoscience students with diverse incoming skills. To test the effectiveness of TMYN, we used changes from pre- to post-test at the student level as a measure of learning gains and thus the effectiveness TMYN.

\section{Participants/Breadth of Sample}

This study was conducted from Fall 2010 through Fall 2013 and included 106 courses offered at 37 institutions (Table 3). The institutions are diverse, ranging from highly selective to open-door; approximately 60\% are bachelor's degreegranting institutions and offered 56 of the 106 courses in this study (Table 3). TMYN was used in multiple semesters/quarters across the range of institutions, illustrating faculty perception that TMYN is a valuable and effective resource for most students.

Faculty from institutions included in this study attended one or more workshops focused on incorporating TMYN into a pre-existing course (Wenner et al. 2011). During the workshop, faculty applied lessons learned from pilot studies and prior implementations of TMYN, designed an implementation by modifying their syllabus, and adapted course materials to include appropriate TMYN modules. ${ }^{3}$ Workshop participants also designed a protocol for the administration of pre- and post-tests as well as the implementation of modules and their associated quizzes. Workshop facilitators guided faculty in effective practices

\footnotetext{
2 https://www.wamap.org/ (last accessed June 1, 2015)

${ }^{3}$ http://serc.carleton.edu/mathyouneed/about/implementations.html (last accessed June 1, 2015)
} 
such as integration of TMYN with the course (Wenner et al. 2011) and revisiting mathematical concepts multiple times in multiple contexts (Manduca et al. 2008; Wenner et al. 2009).

Table 3:

Institutions and Number of Classes ( $n$ ) Implementing TMYN

\begin{tabular}{|c|c|c|c|}
\hline College or University & $\%$ admitted & $\begin{array}{c}\text { total } \\
\text { completers* }\end{array}$ & classes \\
\hline \multicolumn{4}{|c|}{ 4-year College or University } \\
\hline Trinity College, CT & $34 \%$ & 12 & 1 \\
\hline SUNY Geneseo & $36 \%$ & 306 & 3 \\
\hline Lafayette College, PA & $40 \%$ & 42 & 2 \\
\hline Baylor University, TX & $40 \%$ & 392 & 3 \\
\hline SUNY Oneonta & $43 \%$ & 17 & 1 \\
\hline California University of Pennsylvania & $45 \%$ & 91 & 3 \\
\hline West Chester University, PA & $47 \%$ & 87 & 3 \\
\hline Boston University, MA & $51 \%$ & 37 & 5 \\
\hline Hofstra University, NY & $54 \%$ & 19 & 2 \\
\hline California State University-East Bay & $61 \%$ & 6 & 1 \\
\hline Eastern Kentucky University & $66 \%$ & 21 & 3 \\
\hline Fitchburg State University, MA & $69 \%$ & 83 & 5 \\
\hline Ursinus College, PA & $70 \%$ & 17 & 1 \\
\hline Fort Lewis College, CO & $72 \%$ & 184 & 10 \\
\hline Central Michigan University & $73 \%$ & 157 & 2 \\
\hline University of Washington - Tacoma & $78 \%$ & 29 & 1 \\
\hline University of Wisconsin - La Crosse & $78 \%$ & 68 & 1 \\
\hline University of Wisconsin Oshkosh $\dagger$ & $79 \%$ & 220 & 2 \\
\hline University of Maine at Farmington & $82 \%$ & 35 & 2 \\
\hline Morehead State University, KY & $89 \%$ & 42 & 2 \\
\hline University of Texas at El Paso & $99 \%$ & 173 & 3 \\
\hline \multicolumn{4}{|c|}{ 2-year College } \\
\hline Hillsborough Community College, FL & $100 \%$ & 81 & 5 \\
\hline Harold Washington College, IL & $100 \%$ & 2 & 1 \\
\hline McHenry County College, IL & $100 \%$ & 144 & 8 \\
\hline Community College of Baltimore County, MD & $100 \%$ & 23 & 2 \\
\hline North Hennepin Community College, MN & $100 \%$ & 9 & 1 \\
\hline Rochester Community and Technical College, MN & $100 \%$ & 5 & 1 \\
\hline Wake Technical Community College, NC & $100 \%$ & 272 & 7 \\
\hline Bergen Community College, NJ & $100 \%$ & 58 & 4 \\
\hline Ulster County Community College, NY & $100 \%$ & 8 & 1 \\
\hline Linn Benton Community College, OR† & $100 \%$ & 111 & 5 \\
\hline University of South Carolina Lancaster & $89 \%$ & 41 & 2 \\
\hline Lone Star College, TX & $100 \%$ & 78 & 3 \\
\hline Austin Community College, TX & $100 \%$ & 50 & 4 \\
\hline Patrick Henry Community College, VA & $100 \%$ & 25 & 2 \\
\hline Highline Community College, WA & $100 \%$ & 32 & 2 \\
\hline Central Wyoming College, WY & $100 \%$ & 4 & 2 \\
\hline
\end{tabular}

$\dagger$ more than one instructor

* students who completed all or all but one of the assigned modules in their course 
Courses included in this study covered a range of geoscience topics; common first-year introductory courses (Physical Geology, Environmental Geology and Earth System Science) made up approximately 63\% $(n=67)$ of all implementations. Other introductory courses $(n=28)$ were more varied in topic, with titles such as Meteorology, Natural Hazards, Physical Geography and Oceanography. The remaining 11 courses were upper-level courses and included Hydrology ( $n=3)$, Geomorphology $(n=1)$, Structural Geology $(n=4)$ and Geological Methods $(n=3)$. In total, 4486 students were enrolled in the 106 courses involved in this study; individual course enrollments ranged from 5 to 202 students. Although courses were offered at a variety of levels, we examined all uses of TMYN in this study because we observed no significant difference between pre-test scores and subsequent achievement for introductory and upperlevel students (Wenner et al. 2012). The variety of course topics for which faculty desired additional mathematical support emphasizes the need for resources such as TMYN in the geosciences at all levels and underscores the diversity of students who can benefit from the implementation of TMYN.

\section{Use of TMYN}

In the courses included in this study, students completed a pre-test prior to engaging with TMYN; engaged with each module relevant to their course and took the associated post-module quiz; and then took a post-test when all the intervention and associated course content were completed. Equivalent pre- and post-tests consisted of 10-25 questions relating to the assigned modules and assessed quantitative knowledge and the ability to transfer that knowledge to geoscience content. Equivalency in pre- and post-test questions was determined by the format and quantitative skills of the questions; in some cases questions were identical, but in most cases varied slightly by randomizing specific numerical values used in questions (Table 2). In all but five cases, the pre- and post-tests were administered online, sometimes in a computer-equipped classroom; all post-module quizzes were administered using WAMAP.

Because we wished to provide flexibility for instructors to incorporate mathematical skills that span the breadth of topics covered in geoscience courses, instructors designed their own pre- (and equivalent post-) tests, as well as postmodule quizzes so that they included only topics that were covered in the associated course. Each course varied in assigned modules, pre- and post-test questions, and course subjects; thus, the student sample was normalized using standard $Z$ scores (Abdi 2007) so that we could compare results across implementations. Three to eight modules were used in each implementation. Pretest, post-test and post-module quiz scores were converted to percent correct for analysis. 


\section{Measuring engagement and effectiveness}

If geoscience students are to gain skills from TMYN, they must engage with and complete the material contained in the modules. Because we wished to assess the effectiveness of TMYN modules at improving skills, we developed a measure of student engagement with the material. Only students who took post-module quizzes for all or all but one of the assigned modules were considered to have completed the intervention (we call them "completers") and were included in our analysis of learning gains due to the application of TMYN in conjunction with a course. Based on this criterion, 3408 students completed the intervention and 2979 took both the pre and post-test (Table 4A).

In our desire to ensure that all students had maximum access to tools that could help them to succeed, we chose to administer the intervention to all students, precluding a formal randomized control sample. However, 311 students completed both a pre- and post-test but did not engage with a minimum number of TMYN modules, providing a quasi-control group. Although this group is not a randomized control, this group of non-completers (1) received the same information outside of the module as those students who engaged with the modules; and (2) appears representative of the students in the study because average pre-test scores for both groups are similar (Table 4). Thus, we use these non-completers to assess the effectiveness of the intervention at improving learning gains.

\section{Normalizing pre -test data $\left(\mathrm{Z}_{\mathrm{pre}}\right)$}

Because we wanted to maximize use and allow for flexibility in both topic and coverage, instructors tailored the pre-test to their implementation. To be able to compare diverse interventions, we computed a standard $Z$ score (Abdi 2007) using the individual course pre-test mean and standard deviation to calculate students' normalized pre-test scores $\left(Z_{\text {pre }}\right)$ :

$$
Z_{\text {pre }}=\frac{\text { score }_{\text {pre }}-\text { mean }_{\text {course }}}{S D_{\text {course }}}
$$

where score $_{\text {pre }}$ is the individual student pre-test score, mean course $_{\text {is }}$ the course pretest mean, and $S D_{\text {course }}$ is the standard deviation of pre-test scores for the individual course. For the purposes of this study, we subdivided students in the study into four groups based on their $Z_{\text {pre }}$ scores (Table 4): Group 1 with $Z_{\text {pre }}$ less than -1.0 (much below the class mean); Group 2 with $Z_{\text {pre }}$ between -1.0 and 0.0 (below the class mean); Group 3 with $Z_{\text {pre }}$ between 0.0 and 1.0 (above the class mean), and Group 4 with $Z_{\text {pre }}$ greater than 1.0 (much above the class mean; Table 4). These designations will be used throughout the paper. 
Table 4:

\begin{tabular}{|c|c|c|c|c|c|c|c|c|c|c|}
\hline \multicolumn{11}{|c|}{ A: Pre- to Post-test Gains and Mean Normalized Gain* (Hake, 1998) for Completers Disaggregated by $Z_{p r e}{ }^{* *}$} \\
\hline $\begin{array}{c}\text { Group ( range of } \\
\left.Z_{p r e}^{* *}\right)\end{array}$ & $\begin{array}{l}\text { pre-test } \\
\text { (n) }\end{array}$ & $\begin{array}{c}\text { pre- \& } \\
\text { post-test } \\
(n)\end{array}$ & $\begin{array}{l}\text { mean } \\
N G^{* * *} \\
(\%)\end{array}$ & $\begin{array}{c}N G \\
\text { negative } \\
\text { (n) }\end{array}$ & $\begin{array}{c}N G \\
\text { positive } \\
(n)\end{array}$ & $\begin{array}{c}N G=0 \\
(n)\end{array}$ & $\begin{array}{c}\text { pre-test } \\
=100 \% \\
(n)\end{array}$ & $\begin{array}{l}\text { excluded }^{* * *} \\
(N G)\end{array}$ & $\begin{array}{l}\text { Average pre- } \\
\text { test score }\end{array}$ & $\begin{array}{l}\text { Average post- } \\
\text { test score }\end{array}$ \\
\hline Group $1(<-1)$ & 506 & 430 & $44 \%$ & 32 & 394 & 4 & & & $36 \%$ & $64 \%$ \\
\hline Group 2 ( -1 to 0$)$ & 1068 & 915 & $38 \%$ & 119 & 782 & 12 & & & $55 \%$ & $72 \%$ \\
\hline Group $4(>1)$ & 509 & 461 & $11 \%$ & 144 & 237 & 27 & 53 & $\begin{array}{c}20 \\
(-672 \%)\end{array}$ & $85 \%$ & $88 \%$ \\
\hline Totals (n) & 3408 & 2979 & 2883 & 606 & 2233 & 76 & 64 & 32 & & \\
\hline
\end{tabular}

B: Pre- to Post-Test Gains and Mean Normalized Gain* (Hake, 1998) for Non-Completers Disaggregated by $Z_{p r e}{ }^{* *}$

\begin{tabular}{|c|c|c|c|c|c|c|c|c|c|c|}
\hline Group $1(<-1)$ & 122 & 80 & $24 \%$ & 9 & 69 & 2 & & & $31 \%$ & $48 \%$ \\
\hline Group 2 ( -1 to 0$)$ & 179 & 95 & $28 \%$ & 18 & 70 & 7 & & & $52 \%$ & $65 \%$ \\
\hline Group $4(>1)$ & 48 & 28 & $-21 \%$ & 7 & 10 & 2 & 8 & $\begin{array}{c}1 \\
(-467 \%)\end{array}$ & $83 \%$ & $80 \%$ \\
\hline
\end{tabular}

${ }^{*}$ Average of normalized gain [eq. (2)] for all students within a given $Z_{\text {pre }}$ category (Gery 1972, Hake 1998; Kaiser 1989; Williams and Zimmerman 1996).

${ }^{* *} Z_{\text {pre }}$ is the difference between individual pre-test score and course mean divided by standard deviation [eq. (1)]; a standard statistical measure)

${ }^{* * *} 32(\sim 1 \%)$ completers and $1(<<1 \%)$ control student with normalized gains below $-250 \%$ (meaning they lost more than 2.5 times the points between their pretest score and $100 \%$ ) were excluded from these calculations (see text for justification) 


\section{Results}

\section{Pre- and post-test scores}

Table 4 shows pre- and post-test scores (far right columns) for completers (A) and non-completers (B) with scores for both. Course means and individual pre-test scores for 3408 completers and 507 non-completers were used to calculate each student's $Z_{\text {pre }}$ (Eq. (1); Table 4A). Analysis of student scores based on $Z_{\text {pre }}$ group designations shows the disparity in student abilities at the outset of a geoscience course. Average completers' pre-test scores subdivided by $Z_{\text {pre }}$ show a nearly 50 percentage point spread. Students in Group $1(n=506)$ averaged 36\% on the pretest whereas students in Group $4(n=461)$ scored an average of $85 \%$ on the pretest (Table 4A). For the non-completers, the spread is only slightly greater (52\%) with Group 1 scoring 31\% and Group 4 scoring 83\% (Table 4B).

Average post-test scores, which measure student achievement with the use of TMYN, are also shown in Table 4. Post-test scores for completers range from 64\% (Group 1) to 88\% (Group 4); each $Z_{\text {pre }}$ designation shows improvement from pre- to post-test. For the non-completers, student post-test scores vary from $48 \%$ to $80 \%$, and Group 4 shows a decline of 3 percentage points from pre- to posttest. Although pre-test scores are relatively similar between completers and noncompleters in the same group, post-test scores for non-completers are significantly lower than for their counterparts who completed the intervention.

\section{Normalized gain scores}

Normalized gain is a common way to measure learning gains (e.g., Gery 1972; Hake 1998). It is calculated as a percentage using a student's increase from pretest to post-test divided by the maximum possible gain (Gery 1972, Hake 1998):

$$
N G(\%)=\frac{\text { score }_{\text {post }}-\text { score }_{\text {pre }}}{100 \%-\text { score }_{\text {pre }}}
$$

where $N G=$ percent normalized gain; score $_{\text {post }}=$ post-test score (\%); and score $_{\text {pre }}$ $=$ pre-test score $(\%)$. Normalized gain scores are used in this analysis rather than difference scores because the former correlates less well with pre-test scores (corr. coeff. $=-0.221$; Fig 2B) than the latter (corr. coeff. $=-0.530$, Fig. 2A) (Kaiser 1989). If the difference between the pre- and post-test score were to be used, initially high-scoring individuals' changes would be muted (Fig. 2A). An additional advantage to using normalized gain is that by choosing a change measurement that is poorly correlated to the pre-test value, the reliability of this difference is greater (Williams and Zimmerman 1996). 


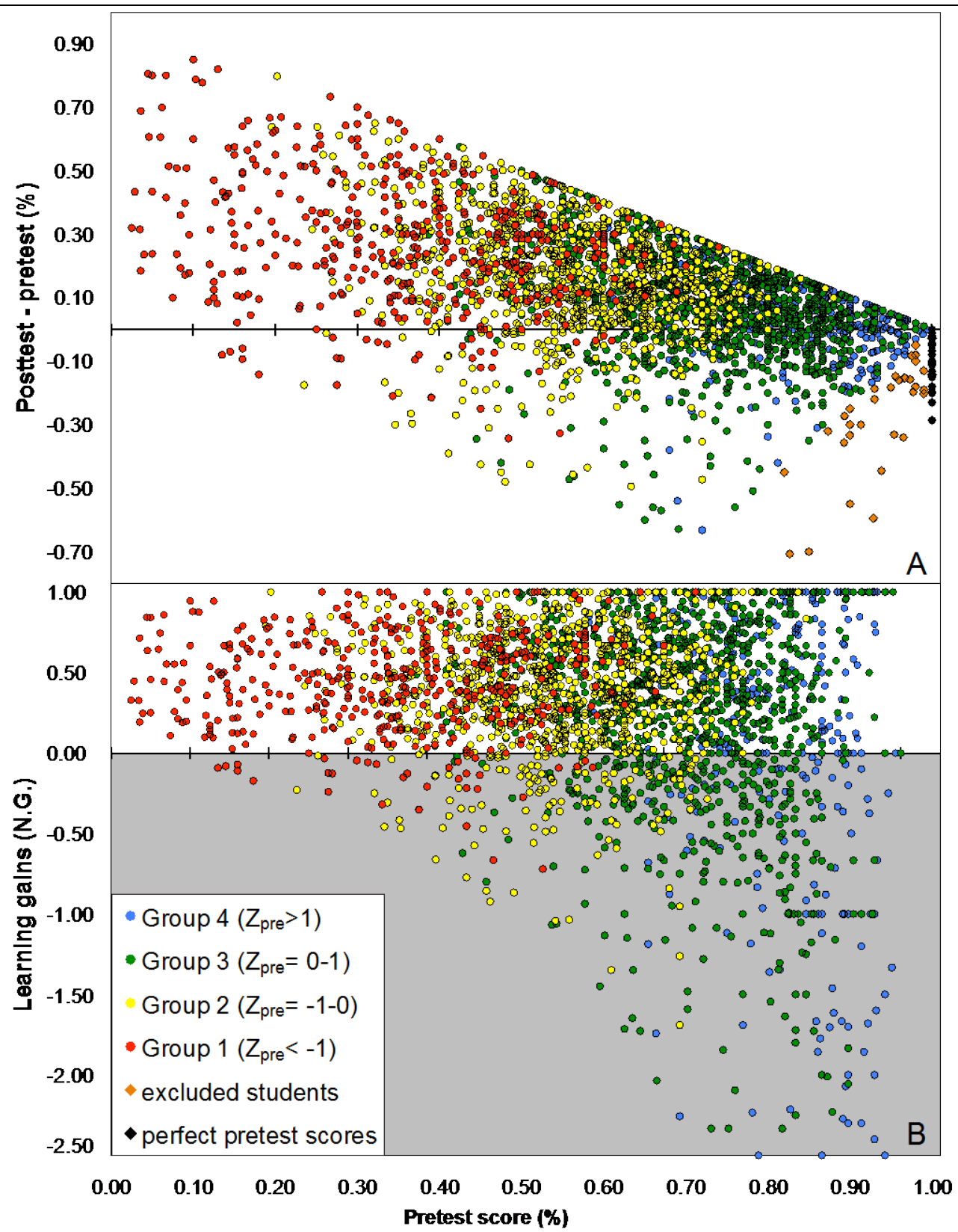

Figure 2. Plots showing $Z_{\text {pre }}$ (symbol color) and correlation between pretest score and (A) simple difference (pre-test - post-test with student scores excluded from calculations of average $N G$ (Table 4) shown in orange (extreme $N G$ ) and black (perfect pre-test) diamonds. This plot illustrates the muting of small but substantial changes in scores for students who score high on the pre-test. Note the clustering of green and blue points for high pre-test scores (B) pre-test score vs. normalized gains $(N G)$. White field shows student with positive gains or no change, approximately $78 \%(n=2309)$ of students. Gray field shows students with negative gains. Orange diamonds in A plot off the bottom of the gray field. 
Normalized gain scores for completers and non-completers in this study with both pre- and post-test scores ( $n=2979$ and $n=311$, respectively) were calculated using Equation (2). Table 4 shows scores subdivided into number of students with positive, negative or zero $N G$ and average $N G$ for each group. Positive $N G$ scores record student improvement throughout the semester; negative $N G$ scores indicate that students had a lower score on the post-test than on the pre-test. Mean normalized gains for each $Z_{\text {pre }}$ group are plotted for comparison in Fig. 3. Note that NG cannot be computed for students who score $100 \%$ on the pre-test (denominator would be zero); therefore, 64 completers who had perfect pre-test scores ( 2\%; Fig. 2A black symbols) and 8 non-completers (2.5\%) were excluded from analysis of $N G$ scores (Table 4; Fig. 3).

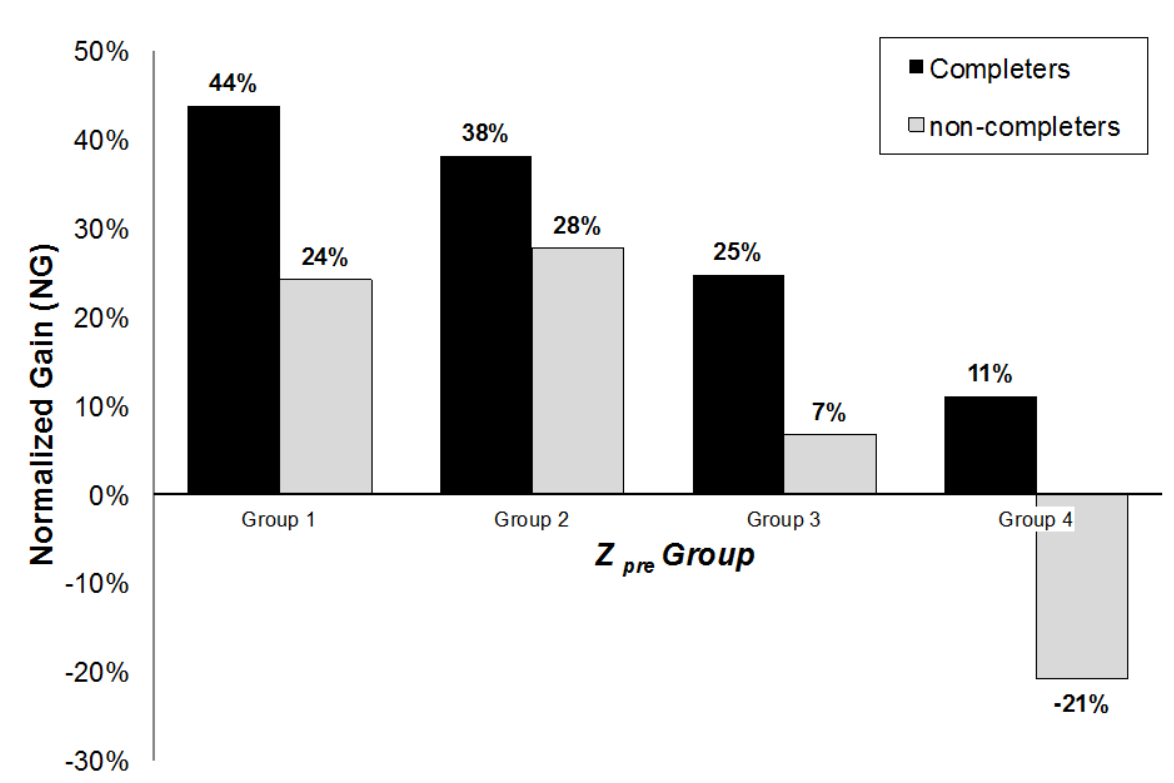

Figure 3. Normalized gains (subdivided by $Z_{\text {pre }}$ ) for completers (black) and non-completers (gray) with both pre- and post-test scores. See Table 4 for $n$ in each group.

Using normalized gain scores can exaggerate small negative changes for students with high pre-test scores, resulting in outliers with extreme negative $N G$ scores (e.g., one student in our sample who scored 99\% on the pre-test and 78.8\% on the post-test resulting in a $N G=-2020 \%$ ). Large negative normalized gains, when included in mean calculations, mask the true effectiveness of the intervention for the majority of high-scoring students. For the purposes of assessing learning gains, we omit 32 completers (1.1\%; orange symbols Fig. 2A) and 1 non-completer $(0.3 \%)$ whose normalized gain scores were equal to or less 
than $-250 \%$. All large negative gains are for students who scored above the mean on the pre-test: 12 in Group 3 and 21 (plus one non-completer) in Group 4. Exclusion of these outliers changes the average $N G$ from $-22 \%$ to $+11 \%$ for Group 4 and from $+21 \%$ to $+25 \%$ for Group 3 completers.

Fig. 3 shows calculated mean normalized gains for completers and noncompleters in each group (Table 4). With the exclusion of the students discussed above, the sample size for $N G$ drops to 2883 completers and 302 non-completers. Completers show positive mean $N G$ s for all groups, with those who score below the mean on the pre-test (Groups 1 and 2) showing greater gains (44\% and 38\%, respectively) than their higher-scoring counterparts (Group 3: 25\%; Group 4: $11 \%)$. Non-completers $(n=302)$ who did not fully engage with the intervention realized diminished normalized gains relative to their fully engaged counterparts in this study. Although Groups 1, 2 and 3 show nominal learning gains (24\%, $28 \%$, and $7 \%$, respectively), Group 4 - the highest scoring individuals - averaged negative $N G$ (-21\%; Fig. 3).

\section{Discussion}

\section{TMYN effectively improves mathematical skills}

The effectiveness of TMYN at improving students' skills is illustrated in Fig. 3. Faculty included in this study used an integrated approach, requiring all students to complete the intervention regardless of pre-test score, a decision based on prior research revealing that completion rates dropped when high-performing students were given the option to forego the modules (Wenner et al. 2011). Completers (black bars) show improvement (on average) across all skill levels whereas noncompleters (gray bars) realize much lower gains (and, in Group 4, gains are actually negative). Non-completers' average scores on the pre-test (Table 4) illustrate that these students (although a considerably smaller sample) represent a relatively good cross-section of the students who participated in the study. Noncompleters and completers received identical course information; yet noncompleters did not fully engage with the tutorials. Students who do not engage with the program consistently score lower on the post-test (Table 4) and realize lower normalized gains (Fig. 3) than their engaged counterparts. The combination of positive learning gains plus consistent learning gains for completers, and lower $N G$ and post-test scores for the quasi-control group support the conclusion that learning gains are, at least in part, the result of employing TMYN tutorials in conjunction with a geoscience class. Furthermore, application of the intervention to all students seems to be justified by the small sample of students with pre- to post-test changes who did not engage with the modules. 


\section{TMYN helps students apply mathematical skills to geoscience}

Mean normalized gains reveal that TMYN modules can help students at all incoming levels to successfully apply mathematics to contextualized quantitative science problems (Fig. 3; Table 4). Because pre- and post-tests included mathematical problems in the context of geoscience, individual learning gains can illustrate increased transfer of skills from mathematics to geoscience. Individual normalized gains vs. pre-test scores for completers are plotted on Fig. 2B; points that fall in the white box represent positive or no change $(80 \% ; n=2309$; Table 4 A); completers with negative $N G$ plot in the gray portion of the plot (20\%; $n=574$ ). Students who initially lack quantitative skills (based on low pre-test scores; red and yellow symbols; Fig. 2B) show the greatest improvements with the implementation of TMYN; nearly 89\% of low-scoring students (1129 of 1345) showed positive normalized gains and cluster in the white field. Although a larger proportion of Groups 3 and 4 (green and blue symbols respectively; Fig 2) have learning gains that reflect lower post-test scores (gray box), a majority of both groups showed positive gains (Group 3=70\%; Group 4=51\%; Table 4). Individual student learning gains on pre- and post-test questions suggest that TMYN supports the successful transfer of students' basic mathematical skills to geoscience topics. Thus, a majority of students who engage with the material, no matter where their pre-test scores fall in relation to their peers, realize learning gains.

\section{TMYN levels the playing field}

The use of TMYN reduced the nearly 50 percentage point difference in pre-test scores between the highest and lowest performing group to less than 25 percentage points between the same groups of students on the post-test (Fig. 4). The average change from pre- to post-test score for 430 students in Group 1 was from 36 to $64 \%$ - a positive change of 28 percentage points - whereas the average post-test score for the 461 students in Group 4 went from 85 to $88 \%$ (Fig. 4; Table 4). The intervening groups showed intermediate change - from $55 \%$ to $72 \%$ for Group 2 and 73 to 80\% for Group 3 students (Fig. 4). Whereas all groups averaged some improvement between pre- and post-test, students who scored lowest on the pre-test showed greater gains than higher-performing students indicating that the integration of TMYN in a course closes the gap between lowand high-performing students (Fig. 4). Indeed, the gap between high- and lowscoring students was reduced by more than $50 \%$ - from 49 percentage points on the pre-test to 24 percentage points on the post-test (Fig. 4) - suggesting that engagement with TMYN helps to "level the playing field" for students of differential abilities. 


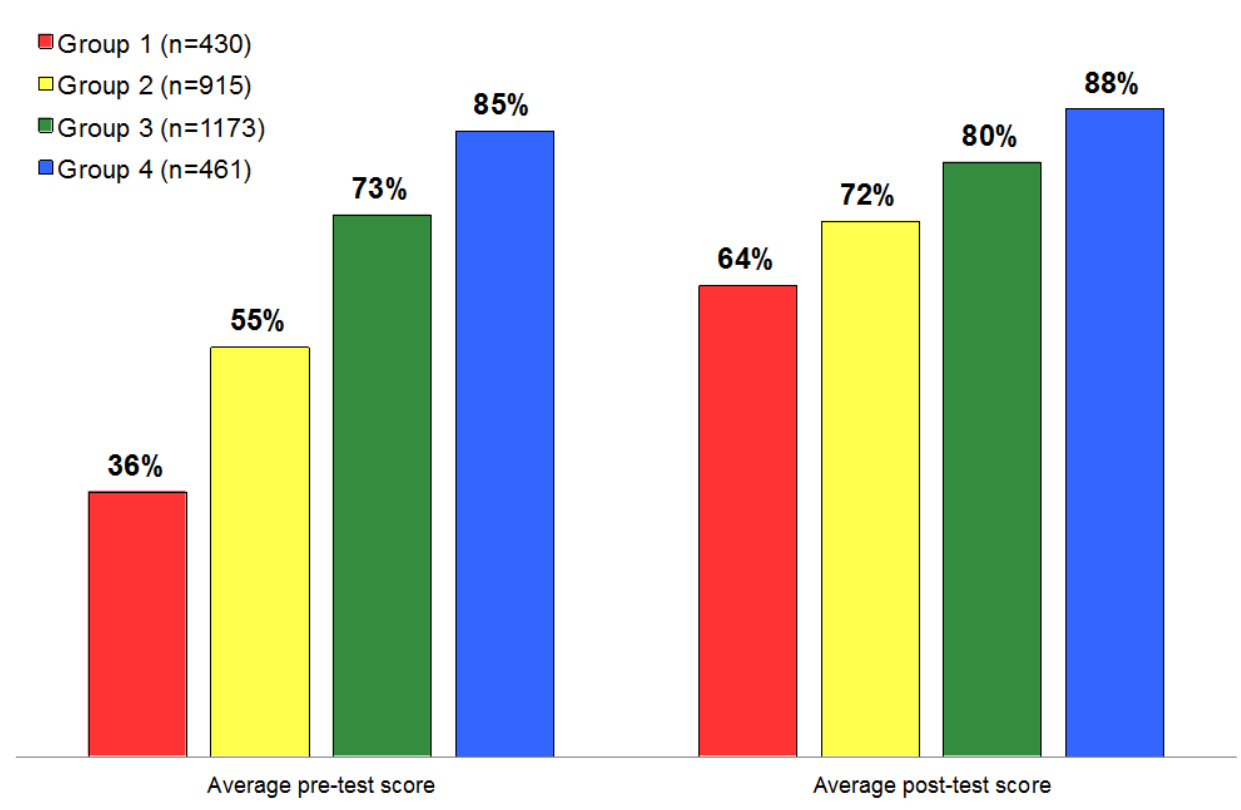

Figure 4. Average pre- and post-test scores for completers in 106 courses that used TMYN $(n=2979)$. Colors represent different groups with warm colors representing low scoring students and cool colors representing high scoring students: red: Group 1 (more than 1 SD below mean); yellow: Group 2 (0-1 SD below mean); green: Group 3 (0-1 SD above mean); blue: Group 4 (>1 SD above mean). Note the wide disparity among pre-test scores that is more than halved (from 4924 percentage points difference) from pre- to post-test, illustrating the leveling of the playing field for students using TMYN.

\section{Conclusions}

Our findings reinforce the idea that students who interact with context-specific quantitative problems, such as those embedded in TMYN, realize learning gains and improve their quantitative skills. Individual learning gains on contextualized pre- and post-test questions illustrate that, when quantitative problem solving is integrated into a science course, modules that support quantitative learning can promote knowledge transfer from mathematical concept to geoscience contexts. Student improvement from pre- to post-test across all levels of initial quantitative skills indicate that The Math You Need, When You Need It is effective at "leveling the playing field," no matter a student's prior preparation. Furthermore, the disparity in post-secondary students' mathematical preparation is not a problem specific to the geosciences; many general science courses require basic quantitative knowledge. Thus, although the current modules are solely in the context of the geosciences, we contend that the support provided by quantitative 
modules integrated into a course could generalize to a variety of science disciplines.

\section{Acknowledgments}

This work is supported by NSF grants DUE-0633402 and -0920583 to Wenner, and DUE-0633755, and -0920800 to Baer. Thank you to Helen Burn for advice about educational protocol and for some of the data analysis. We are grateful to all of the users of TMYN and acknowledge the support of Cathy Manduca, Sean Fox, John McDaris and staff of the Science Education Resource Center at Carleton College. We would also like to thank H. Lehto, S. Schellenberg and an anonymous reviewer for constructive and thoughtful reviews, which greatly improved the manuscript.

\section{References Cited}

Abdi, Hervé. 2007. Z-scores. In Encylopedia of Measurement and Statistics, edited by Neil Salkind. Thousand Oaks, CA: Sage.

Baer, Eric M., Emanuela A. Baer, Helen Burn, Lisa Gilbert, and Carla Whittington. 2002. MathPatch - A "just-in-time" approach to teaching quantitative skills in introductory courses. Geological Society of America Abstracts with Programs, Cordilleran Section, 98th Annual Meeting, May 13-15.

Bailey, Christopher M. 2000. A quantitative approach to introductory geology courses. Journal of Geoscience Education 48: 413-418.

Barkley, Elizabeth F. 2010. Student Engagement Techniques: A Handbook for College Faculty. San Francisco, CA: Jossey-Bass.

Bransford, John D., Ann L. Brown, and Rodney R. Cocking. 1999. How People Learn: Brain, Mind, Experience, and School. Washington, DC: National Academies Press.

DeLaughter, John E, Seth Stein, Carol A. Stein, and Kenneth R. Bain. 1998. Preconceptions abound among students in an introductory earth science course. Eos Trans. AGU 79 (36):429-432. http://dx.doi.org/10.1029/98EO00325

Fike, David S., and Renea Fike. 2008. Predictors of first-year student retention in the community college. Community College Review 36 (2): 68-88. http://dx.doi.org/10.1177/0091552108320222

Gery, F. W. 1972. Does mathematics matter? In Research Papers in Economic Education, edited by Arthur Welsh, 142-157. New York: Joint Council on Economic Education.

Gilbert, Lisa A, Jennifer Stempien, David A McConnell, David A Budd, Katrien J van der Hoeven Kraft, Ann Bykerk-Kauffman, Megan H Jones, Catharine C Knight, Ronald K Matheney, and Dexter Perkins. 2012. Not just "rocks for jocks": Who are introductory geology students and why are they here? Journal of Geoscience Education 60 (4): 360-371. http://dx.doi.org/10.5408/12-287.1

Hake, Richard R. 1998. Interactive-engagement versus traditional methods: A sixthousand-student survey of mechanics test data for introductory physics courses. American Journal of Physics 66: 64-74. http://dx.doi.org/10.1119/1.18809 
Harel, Guershon. 1998. Two dual assertions: The first on learning and the second on teaching (or vice versa) The American Mathematical Monthly 105 (6): 497-507. http://dx.doi.org/10.2307/2589401

-2000. Three principles of learning and mathematics: Particular reference to linear algebra-old and new observations. In On the Teaching of Linear Algebra, edited by J. Dorier, 177-190. Kluwer Academic Publishers.

Kaiser, L. . 1989. Adjusting for baseline: Change or percentage change? Statistics in Medicine 8: 1183-1190. http://dx.doi.org/10.1002/sim.4780081002

Kaseberg, Alice M. 1999. Intermediate Algebra: A just-in-time approach. Stamford, CT: Thomson-Brooks/Cole.

Kenyon, Patricia M. 2000. Building quantitative skills in geoscience courses using homework assignments of increasing difficulty. Journal of Geoscience Education 48 (4): 418-422.

Lutz, Timothy M., and LeeAnn Srogi. 2000. The role of a shadow course in improving the mathematics skills of geoscience majors. Journal of Geoscience Education 48 (4): 474-478.

Macdonald, R. Heather, LeeAnn Srogi, and Glen Stracher, eds. 2000. Special Issue: Building the Quantitative Skills of Students in Geoscience Courses. Vol. 48, Journal of Geoscience Education: National Association of Geoscience Teachers.

Manduca, Cathryn A., Eric M. Baer, Greg Hancock, R. Heather Macdonald, Sam Patterson, Mary E. Savina, and Jennifer M. Wenner. 2008. Making undergraduate geoscience quantitative. EOS 89: 149-150. http://dx.doi.org/10.1029/2008EO160001

Mayer, Richard E. 2001. Multimedia Learning. New York: Cambridge University Press. http://dx.doi.org/10.1017/CBO9781139164603

Mueller, Guntram, and Ronald I. Brent. 2004. Just-In-Time Algebra and Trigonometry for Students of Calculus. Third ed: Addison Wesley.

Perin, D. 2011. Facilitating student learning through contextualization: A review of the evidence. Community College Review 39 (3):268-295. http://dx.doi.org/10.1177/0091552111416227

Planty, Michael, William Hussar, Thomas Snyder, Stephen Provasnik, Grace Kena, Rinkes Dinkes, Angelena KewalRamani, and Jana Kemp. 2008. The Condition of Education 2008. Washington, DC: National Center for Education Statistics, Institute of Education Sciences, U.S. Department of Education.

Salomon, Gavriel, and David N. Perkins. 1989. Rocky roads to transfer: Rethinking mechanisms of a neglected problem. Educational Psychologist 24 (2): 113-142. http://dx.doi.org/10.1207/s15326985ep2402_1

Shea, James H. 1990. Mathematics in physical-geology textbooks. Journal of Geoscience Education 38: 138-148.

Steen, Lynn Arthur. 2004. Achieving Quantitative Literacy: An Urgent Challenge for Higher Education. Washington DC: Mathematical Association of America.

Stevens, Reed. 2000. Who counts what as math?: Emergent and assigned mathematics problems in a project-based classroom. In Multiple Perspectives on Mathematics Teaching and Learning, edited by Jo Boaler, 105-144. Westport, CT: Ablex.

Vacher, H. L. 1998. Computational Geology, 1-Significant Figures! Journal of Geoscience Education 46: 292-295. 
Wenner, Jennifer M., Eric M. Baer, Cathryn A. Manduca, R. Heather Macdonald, Sam Patterson, and Mary E. Savina. 2009. The case for infusing quantitative literacy into introductory geoscience courses. Numeracy 2 (1): Article 4.

http://dx.doi.org/10.5038/1936-4660.2.1.4

Wenner, Jennifer M., H. Burn, and E.M.D. Baer. 2011. The Math You Need, When You Need It: Online modules that remediate mathematical skills in introductory geoscience courses. Journal of College Science Teaching 41: 16-24.

- 2012. Improving geoscience students' quantitative skills with The Math You Need, When You Need It. In the Trenches 2 (2): 1-5.

Wigfield, A., and J. S. Eccles. 2000. Expectancy - value theory of motivation. Contemporary Educational Psychology 25: 68-81. http://dx.doi.org/10.1006/ceps.1999.1015

Williams, R. H., and D. W. Zimmerman. 1996. Are simple gain scores obsolete? Applied Psychological Measurement 20 (1): 59-69. http://dx.doi.org/10.1177/014662169602000106 